\title{
Larval habitat characterization of Anopheles darlingi from its northernmost geographical distribution in Chiapas, Mexico
}

\author{
Cuauhtémoc Villarreal-Treviño, R. Patricia Penilla-Navarro, M. Guadalupe Vázquez-Martínez, \\ David A. Moo-Llanes, Jana C. Ríos-Delgado, Ildefonso Fernández-Salas and Américo D. Rodríguez*
}

\begin{abstract}
Background: Anopheles darlingi is considered the most efficient malaria vector in the Neotropical region. In Mexico, its role as an incriminated vector of Plasmodium has not been confirmed in the Lacandon forest. Similarly, knowledge about bionomic and larval ecology is scarce. The study aim was to identify and describe the larval habitats of An. darlingi in Chiapas, México.

Methods: Standard larval collections were performed in the Lacandon forest region and in the Soconusco region of southern Chiapas from January 2010 to April 2014, including dry and rainy seasons. Mean larval density of An. darlingi was estimated according to hydrological types, and associations between the presence of An. darlingi and environmental factors including ecological parameters and geographic positions were statistically analysed.
\end{abstract}

Results: One hundred and twelve aquatic habitats were analysed, 80 from the Lacandon forest region and 32 from the Soconusco region; $94.64 \%$ of these sites presented anopheline larvae. In total, 10,977 larvae belonging to 11 Anopheles species were collected. The 19 (out of 112) larval habitats positive to An. darlingi were: rain puddles (26.32\%), ground pools (21.05\%), ponds (15.79\%), ditches (15.79\%), river margins (10.53\%) and streams (10.53\%). Overall, the average $( \pm S D)$ larval density was $6.60 \pm 2.41$ larvae per dip. Multiple logistic regression analysis showed that temporary habitats, green algae presence and stagnant water were associated with An. darlingi larval presence. The positive habitats were found in the Lacandon forest region during the rainy season (May-September). No specimens were found in the Soconusco region of the coastal plain of Chiapas.

Conclusion: The mosquito An. darlingi larval habitats were found in different hydrological types. The habitat stability, presence of algae and water current were the main factors for An. darlingi larval occurrence. The information on the characteristics of the larval habitats of An. darlingi will be useful in sustainable programmes for malaria control in the Lacandon forest region, Chiapas.

Keywords: Anopheles darlingi, Lacandon forest, Malaria, Anopheline habitats

\section{Background}

Malaria continues to be a global public health problem, and it is considered the most important vector-borne infectious disease in the world, including Mexico [1]. Anopheles darlingi, a member of the Albitarsis section of

\footnotetext{
*Correspondence: americo@insp.mx

Centro Regional de Investigación en Salud Pública/Instituto Nacional de Salud Pública (CRISP/INSP), 19 Poniente y 4ta Avenida Norte, C.P.
} 30700 Tapachula, Chiapas, Mexico the Nyssorhynchus subgenus is considered the dominant and most dangerous malaria vector in the Neotropical region [2, 3]. It is widely distributed in Central and South America, from southern Mexico to northern Argentina. It has not been described in Nicaragua and Costa Rica [2, 4, 5], and it was recently reported in Panama [6].

In Iquitos, Peru, An. darlingi populations increased dramatically in the 1990s, after deforestation and the creation of new human settlements and roads [7]. The increase in malaria cases also occurred specifically due 
by Plasmodium falciparum [8]. In Central and South America, this species is considered the primary malaria vector of Plasmodium vivax and $P$. falciparum $[9,10]$. In susceptibility experiments with P. falciparum in Belize, it was found that $A n$. darlingi is the most susceptible species, with $41.0 \%$ positivity in their salivary glands and more than 200 sporozoites per gland [11]. In Mexico, it has not been found infected in its natural state. However, in the Lacandon forest region, this species is considered to participate as a secondary vector transmitting malaria $[12,13]$.

In Belize, larvae prefer those habitats with available organic matter found in river margins, and shaded areas with submerged plants in fluvial environments [14]; preference is mainly associated with floating detritus [15]. In Brazil and Colombia, larvae are usually found in shaded breeding habitats with clean running water and organic matter $[16,17]$. This species is commonly found in rural areas and small localities, but it is unlikely to be found in undisturbed areas [18].

Between 2006 and 2008, the state of Chiapas presented the highest number of malaria cases in Mexico (58.3\% of all cases in the country), mainly along the Mexico-Guatemala border (Lacandon forest and Soconusco focus, Chiapas) [19]. In Mexico, An. darlingi was reported in the Anaite village alongside the Usumacinta River in the Lacandon forest (Chiapas), and in Teapa (Tabasco) at $72 \mathrm{~m}$ above sea level (masl) [20, 21]. Larval habitats were described as sunny, clean fresh water with low movement, $\mathrm{pH}$ of 7.1-7.2, temperature between 17.5 and $33{ }^{\circ} \mathrm{C}$, and always present in low densities [22]. However, this information is outdated and the larval ecology studies for this species have not been continued, in spite that the Lacandon forest region is hyperendemic for malaria. During the 1960s and 1970s, native Mexicans from the Yucatan Peninsula and later from other northern states of Mexico migrated to Chiapas specifically to the Lacandon forest region [23]. Furthermore, this area has been subject to extensive and accelerated deforestation from 1954 to 2000 , with almost $30 \%$ of trees felled. The new settlements, as well as unregulated logging and forest fires caused changes in the orography of the region. However, the impact of these changes in vectors population density and transmission dynamics are still unknown. Similar changes are known to result in the occurrence of new larval habitats and the increase of adult An. darlingi densities in the Amazon rain forest of Peru [7, 24].

This study aims to identify and describe An. darlingi larval habitats in two geographic regions of southern Chiapas, Mexico. These findings will be useful in determining the current biology and ecology of the species, and will help in planning prevention and control activities for this important malaria vector in the Lacandon forest region.

\section{Methods}

\section{Study design}

Larvae collection sites were determined according to previous reports for An. darlingi distribution $[21,22]$ and potential sites by a prediction model in the Malaria Atlas Project [25] in the Lacandon forest region $\left(17^{\circ} 37^{\prime} 30.69^{\prime \prime} \mathrm{N}, 92^{\circ} 01^{\prime} 41.56^{\prime \prime} \mathrm{W}\right.$ to $16^{\circ} 5^{\prime} 8.91^{\prime \prime} \mathrm{N}$, $\left.90^{\circ} 28^{\prime} 0.37^{\prime \prime} \mathrm{W}\right)$ and the southern coastal plain named the Soconusco region $\left(15^{\circ} 39^{\prime} 21.05^{\prime \prime} \mathrm{N}, 93^{\circ} 22^{\prime} 24.95^{\prime \prime} \mathrm{W}\right.$ to $\left.14^{\circ} 32^{\prime} 6.50^{\prime \prime} \mathrm{N}, 92^{\circ} 13^{\prime} 23.33^{\prime \prime} \mathrm{W}\right)$. Both areas are endemic for malaria and are used as migration routes by people traveling to northern Mexico and the United States [26]. The Lacandon forest region, including "The Montes Azules Biosphere Reserve", is delimited by the Lacantun, Jatate and Lacanja rivers, all of which flow into the Usumacinta River. The climate in the region is tropical wet (Koppen classification, $A f, A m$ ), with abundant rain from May to November. Annual median temperature is $24-26{ }^{\circ} \mathrm{C}$, and the annual precipitation ranges between 2500 and $3500 \mathrm{~mm}$ [27]. Altitude for the region is 120-840 masl [23]. The Soconusco region has a tropical wet and dry climate (Koppen classification, Aw), with a rainy season from May to October, annual mean temperature of $27^{\circ} \mathrm{C}$ and annual precipitation of $2800 \mathrm{~mm}$. The altitude in the region ranges from sea level next to the Pacific Ocean to 500 masl at the foothills [27]. The Chiapas coastal plain comprises extensive banana and mango plantations, swamps, and a livestock grazing areas (0-150 masl); while the regions near the mountains comprise large coffee plantations (150-550 masl).

\section{Anopheles darlingi field collection}

Diverse larval habitats were visited from January 2010 to April 2014, including dry and rainy seasons. In the Lacandon forest, larvae were collected from rural and semi-urban areas, alongside highways and roads. In the Soconusco region, located at the south of the coastal plain of Chiapas, different agro-ecological zones were visited starting on the border with Guatemala to the northwest $150 \mathrm{~km}$ along the coastline, and from sea level to 500 masl, following the course of the Coatán River.

Larval index (LI) or larval density was expressed as total number of larvae per dip/the number of dips $x$ the number of habitats [28]. Sampled water was poured into a white tray, using a standard $500 \mathrm{ml}$ dipper [29]. Larvae (I to IV instar) were counted and packed in plastic bags (Whirl-Pak ${ }^{\circledR}$ ) and placed into an ice chest. The anopheline larvae sampled from each larval habitat were reared in separate trays until adulthood in the insectary at the Centro Regional de Investigación en Salud Pública 
(CRISP) in Tapachula, Chiapas, to determine the species according to a morphological based key [30].

For each aquatic habitat, environmental variables were recorded during larval sampling, including hydrological types [31]. Average water depth was measured from three different points of each larval habitat using a $1 \mathrm{~m}$ wooden ruler introduced it until reached the solid bottom. Turbidity was determined visualizing a water sample in a transparent bottle and placing it on a light background and recorded as clear or turbid [32]. Vegetation coverage, surface detritus, presence of green algae, and intensity of light were estimated by visual assessment as the percentage of total surface covered. The aquatic vegetation was categorized as emergent, floating or submerged and none when were not present. Emergent plants include both aquatic and immersed terrestrial vegetation. Water current, was estimated as stagnant, slow or high [33, 34]. Habitat stability was categorized as permanent or temporal. Permanent habitats were considered as those that remained during the dry season and temporary as those that appears only during the rainy season. The elevation and coordinates (longitude and latitude) of all selected breeding sites were recorded in situ using a portable GPS receiver. The distribution map and the calculation of distances between the larval habitats and the nearest house were made using the software Esri ${ }^{\circledR}$ ArcMap the geomatics suite Arc GIS 10.3 software.

\section{Data analysis}

Mann-Whitney U test was used to compare the larval index or density of anopheline species collected between Lacandon forest and Soconusco regions. Pearson correlation was used to determine the association between An. darlingi larval density with rainfall and the relationship between $A n$. darlingi larvae presence with other anopheline species coexisting in the same larval habitat. One-way analysis of variance (ANOVA) was used to analyse the abundance between species. Multiple logistic regression analyses were used to determine the association between environmental variables and the occurrence of An. darlingi larvae. Statistical analysis was performed using JMP 7.0.1 software (SAS Institute, Cary, NC, USA).

\section{Results}

\section{Anopheles species abundance}

Each aquatic habitat was visited from 19 to 25 times during 4 years. A total of 10,977 anopheline larvae were collected of which 10,421 adults were obtained, belonging to 11 Anopheles species. Larval index (LI) showed significant differences between the Lacandon forest $(\mathrm{LI}=2.9)$ and Soconusco regions $(\mathrm{LI}=3.6)$
(Mann-Whitney $\mathrm{U}=682 ; p<0.0001)$. An. darlingi was found only in the Lacandon forest region, in northeastern Chiapas (between $16^{\circ} 9^{\prime} 36.00^{\prime \prime} \mathrm{N}, 90^{\circ} 52^{\prime} 48.10^{\prime \prime} \mathrm{W}$; and $17^{\circ} 14^{\prime} 15.50^{\prime \prime} \mathrm{N}, 91^{\circ} 44^{\prime} 28.99^{\prime \prime} \mathrm{W}$ to Mexican border with Guatemala). No specimen was found in the south coastal region of Chiapas (Fig. 1). The An. darlingi larvae occurrence was positively correlated with the rainy season in the Lacandon forest region $\left(\mathrm{R}^{2}=0.609 ; p=0.036\right)$ (Fig. 2).

Species abundance showed significant differences $(P<0.05)$ : Anopheles albimanus (mean $=71.6$; $\mathrm{SD} \pm 128.97)(55.68 \%)$ and Anopheles pseudopunctipennis $($ mean $=92.6 \pm 154.17)(41.78 \%)$, were the most abundant in comparison with Anopheles vestitipennis (mean $=11.9 \pm 13.10)(1.14 \%)$, An. darlingi (mean $=3.5 \pm 2.412)(0.63 \%)$, Anopheles punctimacula $($ mean $=4.6 \pm 2.073)(0.22 \%)$, Anopheles hectoris (mean $=20.0 \pm 0.0)(0.19 \%)$, Anopheles crucians $($ mean $=4.0 \pm 4.24)(0.15 \%)$, Anopheles apicimacula (mean $=4.7 \pm 3.51)(0.13 \%)$, Anopheles gabaldoni $($ mean $=2.5 \pm 0.70)(0.05 \%)$, Anopheles argiritarsis (mean $=1.0 \pm 0.0)(0.01 \%)$ and Anopheles eiseni $($ mean $=1.0 \pm 0.0)(0.01 \%)(\mathrm{F}=5.2 ; \mathrm{df}=10,120$; $p=0.0001$ ) (Fig. 3).

In the hydrological types positive for An. darlingi larvae, other species were found coexisting in the following total percentages: An. pseudopunctipennis (45.66 \%), An. albimanus (42.72 \%), An. vestitipennis (6.52\%), An. darlingi $(4.73 \%)$ and An. crucians $(0.35 \%)$. There was a positive correlation between presence of An. darlingi and An. albimanus $\left(\mathrm{R}^{2}=0.957 ; p=0.001\right)$, An. pseudopunctipennis $\left(\mathrm{R}^{2}=0.777, p=0.040\right)$ and An. crucians $\left(\mathrm{R}^{2}=0.785\right.$, $p=0.036)$, but not with An. vestitipennis $\left(\mathrm{R}^{2}=0.635\right.$, $p=0.125)$ (Table 1$)$.

\section{Habitat types of Anopheles darlingi}

A total of 112 aquatic habitats were sampled throughout the study, 80 for the Lacandon forest region and 32 for the Soconusco region. A total of 106 (94.64 \%) larval habitats were positive for anopheline larvae and only 19 (16.94 \%) were positive for An. darlingi larvae. All An. darlingi positive habitats were present in a deforested area of the Lacandon forest region.

A total of $66 \mathrm{An}$. darlingi larvae were captured during the study in six different hydrological types distributed as follows: ponds (27.27\%), ground pools (22.72\%), streams $(18.18 \%)$, rain puddles (16.66 \%), ditches (7.57 \%), and river margins $(7.57 \%)$ (Table 1$)$. The mean $( \pm \mathrm{SD})$ larval density in all positive hydrological types was low with a $6.6 \pm 0.2 .41 \mathrm{LI}$ (Table 2). To observe the different hydrological types in more detail see (Additional file 1). There was no association between the hydrological type and An. darlingi larval abundance (Table 3). 


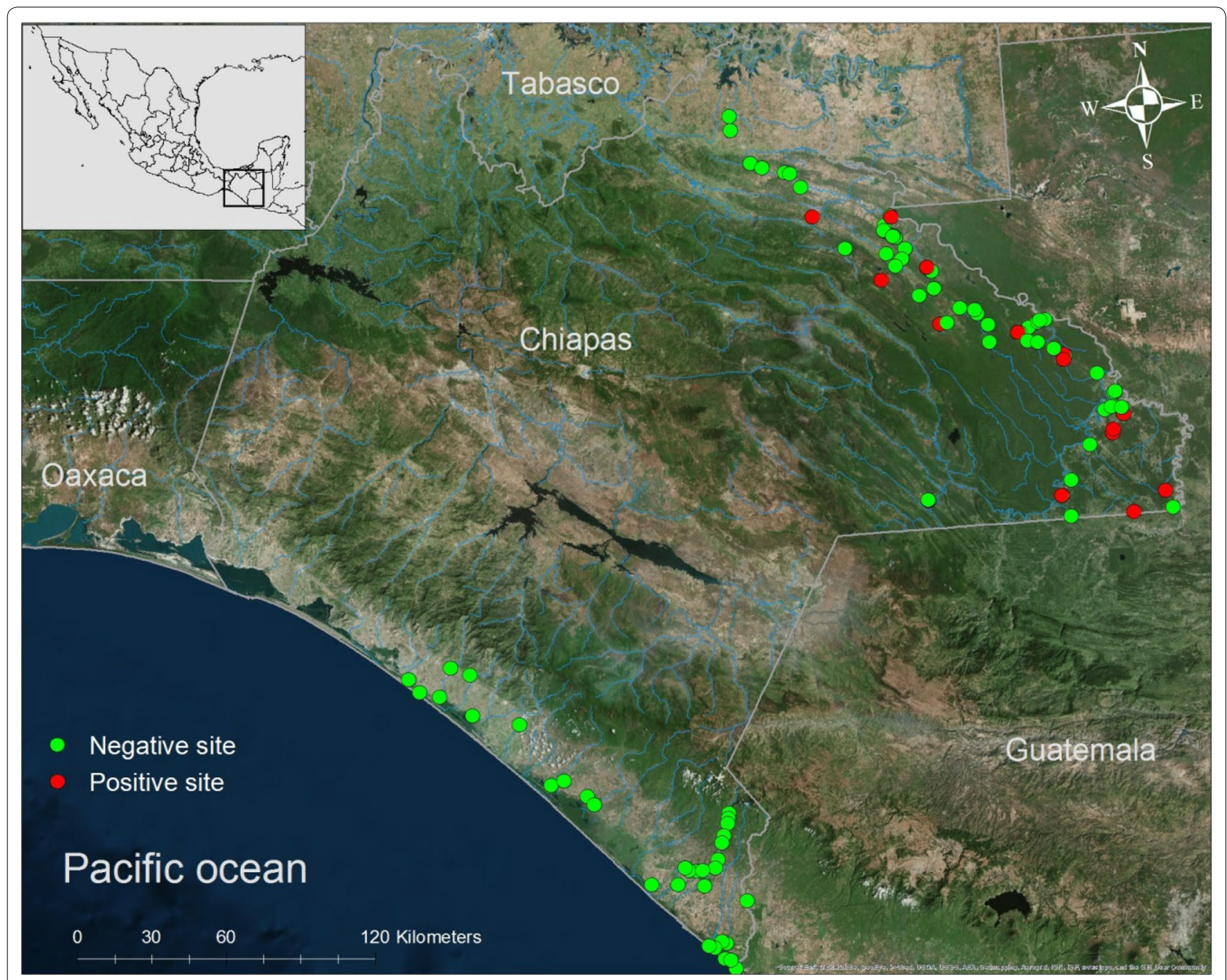

Fig. 1 Study area indicating the negative and positive larval habitats of Anopheles darlingi in Chiapas, Mexico

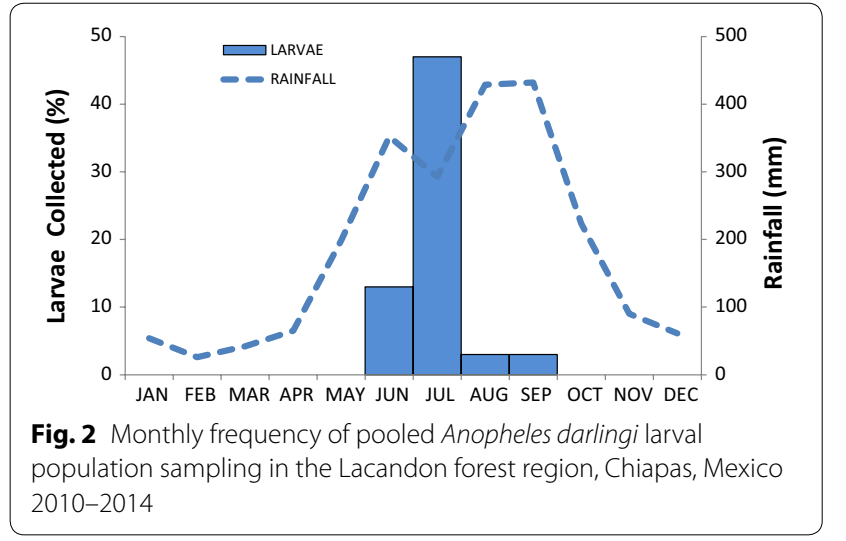

\section{Habitat description of Anopheles darlingi}

Multiple logistic regression showed that presence of algae, habitat stability, and water current were the principal factors associated for An. darlingi larvae occurrence in the habitat (Table 3). Green algae were presented in $84.21 \%$ of the larval habitats and significantly associated $(p=0.046)$ with the occurrence of larvae. The $A n$. darlingi larvae were mainly present in temporary habitats during the rainy season $(p=0.022)$. Larval density was positively associated with water movement $(p=0.000)$, finding larvae in stagnant water or slow movement, but never in high movement (Table 3).

\section{Discussion}

In the present study An. darlingi larvae were present in different hydrological types, associated with An. albimanus, An. pseudopunctipennis and An. crucians. These associations were consistent with the data documented from Belize, where An. darlingi was also found coexisting with An. albimanus and An. pseudopunctipennis [14]. 

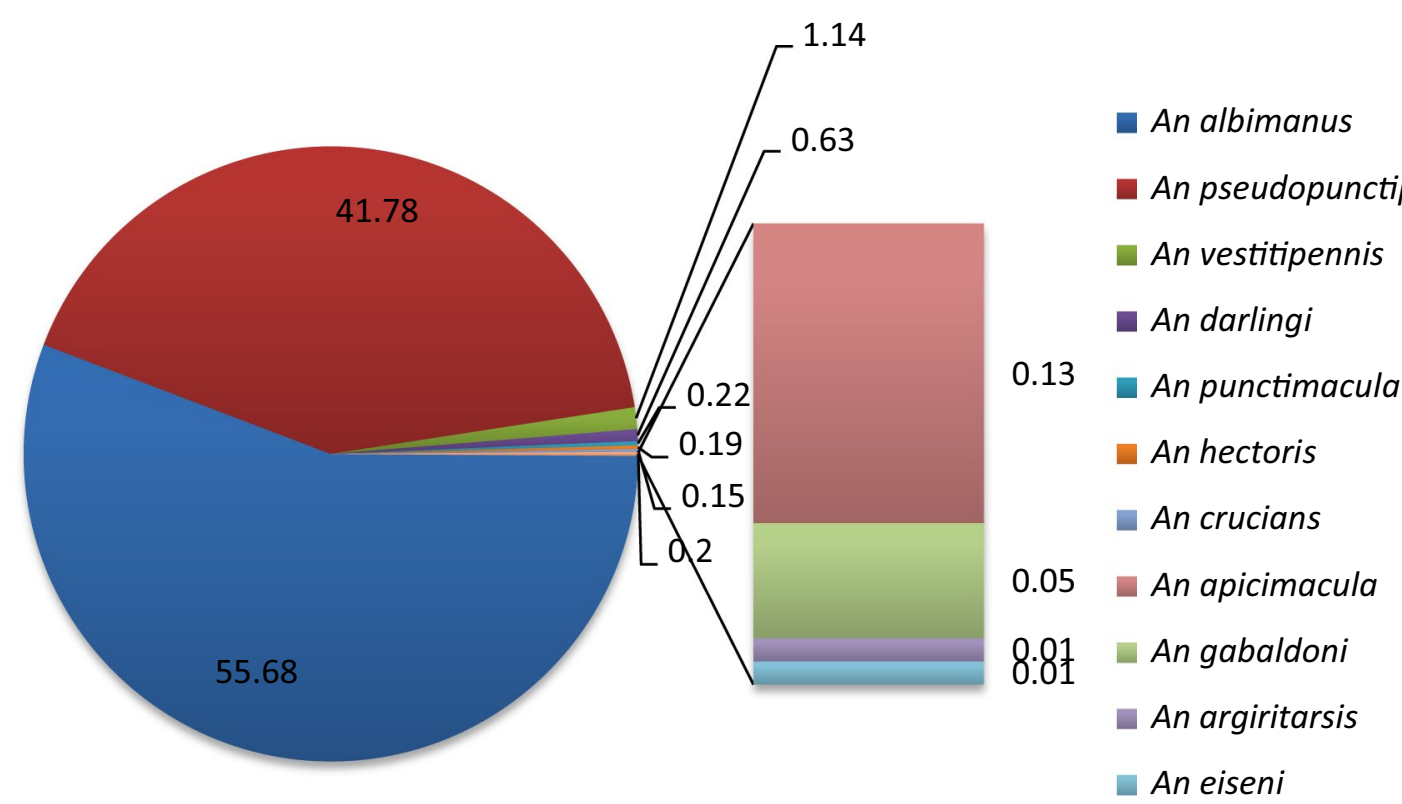

Fig. 3 Anopheline species composition and abundance (percent) in the Lacandon forest and Soconusco regions, Chiapas, Mexico

Table 1 Anopheline species composition (\%) coexisting with An. darling larvae in the Lacandon forest, Chiapas

\begin{tabular}{lccccccc}
\hline Hydrologic type & Total larvae & Ditches & Ground pools & Ponds & Rain puddles & River margins & Streams \\
\hline An. pseudopunctipennis & 637 & 1.72 & 5.33 & 87.44 & 2.82 & 1.72 & 0.94 \\
An. albimanus & 596 & 0 & 29.36 & 41.10 & 19.29 & 4.69 & 0 \\
An. vestitipennis & 91 & 76.92 & 0 & 0 & 23.07 & 7.53 \\
An. darlingi & 66 & 7.57 & 22.72 & 27.27 & 16.66 & 7.57 & 0 \\
An. crucians & 5 & 0 & 0 & 20 & 0 & 3.15 & 30 \\
Total & 1395 & 6.16 & 16.06 & 58.85 & 11.83 & 3.94 \\
\hline
\end{tabular}

Table 2 Larval abundance of Anopheles darlingi in different hydrological types in the Lacandon forest, Chiapas, Mexico

\begin{tabular}{lclll}
\hline $\begin{array}{l}\text { Hydrological } \\
\text { types }\end{array}$ & $\begin{array}{l}\text { No } \\
\text { sampled }\end{array}$ & $\begin{array}{l}\text { No } \\
\text { positive }\end{array}$ & $\begin{array}{l}\text { \% } \\
\text { positive }\end{array}$ & $\begin{array}{l}\text { Larval } \\
\text { density }^{\mathbf{a}}\end{array}$ \\
\hline Rain puddles & 24 & 5 & 26.32 & $2.20 \pm 1.304$ \\
Ground pools & 6 & 4 & 21.05 & $3.75 \pm 1.500$ \\
Ponds & 14 & 3 & 15.79 & $6.00 \pm 3.000$ \\
Ditches & 4 & 3 & 15.79 & $1.66 \pm 1.155$ \\
River margins & 17 & 2 & 10.53 & $2.50 \pm 0.707$ \\
Streams & 6 & 2 & 10.53 & $6.00 \pm 4.243$ \\
River Pools & 5 & 0 & 0 & 0 \\
Lagoons & 4 & 0 & 0 & 0 \\
Total & 80 & 19 & 100 & $6.60 \pm 2.41$ \\
\hline
\end{tabular}

a Mean \pm SD
Anopheles darlingi larvae were found only during the rainy season, from June to September, with a peak in July. During August and September it was very difficult to find An. darlingi larvae, because the water current at hydrological types such as streams, river margins, river pools, and ditches increased with the rain, washing away larval breeding habitats [35]. Also, hydrological types such as rain puddles, ground pools, and ponds increased in size during the rainy season, making it difficult to find $A n$. darlingi larvae. About $53 \%$ of the breeding habitats disappeared during the dry season, reducing the availability of larval habitats of An. darlingi [35].

The results in this study showed that rain puddles had the greatest percentage of positive habitats followed by ground pools and ponds; the less productive are the 
Table 3 Logistic regression for Anopheles darlingi larvae abundance in the Lacandon forest and Soconusco regions, Chiapas, México

\begin{tabular}{|c|c|c|c|c|c|c|c|}
\hline \multirow[t]{2}{*}{ Variable } & \multirow[t]{2}{*}{ B } & \multirow[t]{2}{*}{ SE } & \multirow[t]{2}{*}{ df } & \multirow[t]{2}{*}{ Sig } & \multirow[t]{2}{*}{ OR } & \multicolumn{2}{|c|}{$95 \% \mathrm{Cl}$ for OR } \\
\hline & & & & & & Lower & Upper \\
\hline Interception & -0.015 & 0.175 & & 0.279 & -0.087 & -0.362 & 0.331 \\
\hline Water depth & & & 2 & 0.110 & & & \\
\hline $0-100$ & 0.043 & 0.021 & 1 & 0.043 & 2.054 & 0.001 & 0.084 \\
\hline $101-300$ & 0.000 & 0.000 & 1 & 0.934 & $65,535.000$ & 0.000 & $65,536.000$ \\
\hline $301-800$ & 0.052 & 0.162 & 1 & 0.965 & 0.321 & -0.269 & 0.373 \\
\hline Turbidity & -0.68 & 0.072 & 1 & 0.347 & -0.944 & -0.211 & 0.075 \\
\hline Coverage & & & 2 & 0.200 & & & \\
\hline $0-30 \%$ & -0.090 & 0.107 & 1 & 0.401 & -0.843 & -0.303 & 0.122 \\
\hline $31-60 \%$ & 0.000 & 0.000 & 1 & 0.690 & $65,535.000$ & 26.000 & $65,546.000$ \\
\hline $61-100 \%$ & -0.082 & 0.150 & 1 & 0.530 & -0.548 & -0.379 & 0.215 \\
\hline Detritus & & & 2 & 0.600 & & & \\
\hline Low & -0.384 & 0.142 & 1 & 0.008 & -2.699 & -0.666 & -0.102 \\
\hline Moderate & -0.080 & 0.115 & 1 & 0.486 & -0.699 & -0.308 & 0.147 \\
\hline High & 0.000 & 0.000 & 1 & 0.230 & $65,535.000$ & $19,849.000$ & $65,595.000$ \\
\hline Presence of algae & 0.151 & 0.075 & 1 & 0.046 & 2.021 & 0.003 & 0.298 \\
\hline Intensity of light & & & 2 & 0.079 & & & \\
\hline Light & 0.000 & 0.000 & 1 & 0.580 & $65,535.000$ & $18,679.000$ & $65,538.000$ \\
\hline Light/shade & 0.054 & 0.129 & 1 & 0.960 & 0.418 & -0.202 & 0.310 \\
\hline Shade & 0.108 & 0.115 & 1 & 0.351 & 0.937 & -0.120 & 0.336 \\
\hline Vegetation & & & 2 & 0.550 & & & \\
\hline Emergent & 0.236 & 0.138 & 1 & 0.123 & 1.704 & -0.039 & 0.510 \\
\hline Floating/submerged & 0.000 & 0.000 & 1 & 0.583 & $65,535.000$ & 1657.000 & $65,536.000$ \\
\hline None & 0.216 & 0.094 & 1 & 0.890 & 2.304 & 0.030 & 0.403 \\
\hline Water current & & & 2 & 0.000 & & & \\
\hline Stagnant & 1.000 & 0.110 & 1 & 0.000 & 9.080 & 0.781 & 1.218 \\
\hline Slow & 0.096 & 0.081 & 1 & 0.236 & 1.192 & -0.064 & 0.256 \\
\hline High & 0.000 & 0.000 & 1 & 0.260 & $65,535.000$ & 1487.000 & $65,539.000$ \\
\hline Habitat stability & 0.188 & 0.081 & 1 & 0.022 & 2.327 & 0.028 & 0.349 \\
\hline Elevation & 0.134 & 0.268 & 1 & 0.616 & 0.503 & -0.396 & 0.665 \\
\hline Distance to nearest house & & & 2 & 0.580 & & & \\
\hline $0-2.66 \mathrm{~km}$ & 0.085 & 0.140 & 1 & 0.545 & 0.607 & -0.193 & 0.363 \\
\hline $2.67-5.89 \mathrm{~km}$ & 0.121 & 0.161 & 1 & 0.456 & 0.748 & -0.199 & 0.441 \\
\hline $5.90-12.1 \mathrm{~km}$ & 0.000 & 0.000 & 1 & 0.630 & $65,535.000$ & 5276.000 & $65,535.000$ \\
\hline Region & 0.085 & 0.058 & 1 & 0.650 & 1.468 & -0.030 & 0.199 \\
\hline Hydrological type & & & 10 & 0.810 & & & \\
\hline Ditches & 0.000 & 0.011 & 1 & 0.976 & -0.030 & -0.022 & 0.022 \\
\hline Gravel pits & 0.283 & 0.292 & 1 & 0.334 & 0.971 & -0.296 & 0.863 \\
\hline Ground pools & 0.193 & 0.284 & 1 & 0.498 & 0.680 & -0.371 & 0.757 \\
\hline Irrigation canal & 0.142 & 0.243 & 1 & 0.559 & 0.586 & -0.339 & 0.624 \\
\hline Lagoon & 0.135 & 0.277 & 1 & 0.627 & 0.488 & -0.415 & 0.686 \\
\hline Marshes & 0.159 & 0.241 & 1 & 0.505 & 0.669 & -0.312 & 0.630 \\
\hline Ponds & 0.349 & 0.241 & 1 & 0.150 & 1.452 & -0.128 & 0.827 \\
\hline Rain puddles & 0.140 & 0.318 & 1 & 0.660 & 0.441 & -0.491 & 0.772 \\
\hline River margins & -0.047 & 0.303 & 1 & 0.877 & -0.156 & -0.649 & 0.554 \\
\hline River pools & 0.140 & 0.337 & 1 & 0.678 & 0.417 & -0.529 & 0.810 \\
\hline Pools & 0.000 & 0.000 & 1 & 0.690 & $65,535.000$ & 527.000 & $65,535.000$ \\
\hline Streams & 0.135 & 0.277 & 1 & 0.090 & 0.488 & -0.415 & 0.686 \\
\hline
\end{tabular}

OR odds ratio, $C l$ confidence interval, Sig significant, $d f$ degrees of freedom 
river margins and streams. These larval habitats in the Lacandon forest region were the consequence of product human activities in the area; including excessive logging, construction of rural and public roads, and the introduction of livestock. Similar results were found in the Peruvian tropical rainforest, where a strong association of large ponds and larvae was detected due to changes in the natural habitats caused by human alterations [7]. That promoted the development of $A n$. darlingi, in such a way that biting rate was 278 times higher in deforested regions as compared to forested, and the presence of human populations was indicator of An. darlingi larvae [24]. Water bodies such as lakes, ponds and river margins, inside the "Montes Azules" ecological reserve, did not present An. darlingi larvae; this is consistent with the findings of studies done in the Brazilian Amazon, where the lowest anthrophilic mosquito index found was in the Maraca ecologic reserve [18]. In the Peruvian Amazon, An. darlingi larvae were breeding less frequently in water bodies that were surrounded predominantly by forest [24]. In Colombia, An. darlingi is a riverine mosquito that prefers living in rural areas of low elevation within the jungle [17]. Similarly in Panama, it prefers to inhabit areas that have been little disturbed by humans [6]. These differences in $A n$. darlingi habitat preference of either forest areas or human-altered areas is very complex and will depend on the regional ecology of each site [36, 37].

Preferred breeding habitats for An. darlingi have been described in different environments of Central and South America [14-18, 35]. In Mexico, An. darlingi has been only reported in the Lacandon forest region in Chiapas and Teapa, Tabasco in the 1940s and 1950s [20-22]. These old reports describe larval habitats as: sunny, low-movement freshwater bodies in the river margins of the Usumacinta River. In this study, no An. darlingi larvae were found in the Usumacinta River margins. This is probably because it requires intensified sampling mainly in the dry season, because that is when ponds are formed in the margins of the river, so this species occurrence should not rule out in some areas of the Usumacinta River. Another probable habitat for An. darlingi in Mexico is the state of Quintana Roo, because it borders with Belize, which has an important role in malaria transmission. However, An. darlingi has not been found in this region to date [38]. This study was performed over 4 years because the larvae were found in very low densities and sampling was made difficult by the inaccessibility of the larval habitats. Similar reports such as one from Belize mention that An. darlingi breeding habitats are difficult to find, such that the authors did not collect any $A n$. darlingi larvae after 2 years of intensive search. However, An. darling $i$ habitats were found in open water areas nearby rivers, with the help of satellite imagery [39].
The results of this study showed no difference between sunny and shaded habitats, indicating that the larvae do not have a defined preference for light. This contrasts with the findings of previous studies from Mexico [19, 20], where it is mentioned that the An. darlingi larvae prefer sunny habitats, just as in Peru, where An. darlingi larval densities increased with the amount of light [24]. Reports from Panama [6], Belize [14], and Colombia [17], mention that larvae prefer shaded habitats. Reports from Panamá and Belize state that An darlingi larvae prefer clear water with a slow flow, which is consistent with the results of this study [14, 17]. In this study, the presence of algae in the breeding habitats was a positive indicator for the presence of An. darlingi larvae as found in Belize and Peru studies [14, 24]. This positive correlation can be explained because larvae feed on the algae and use the algae to hide from predators [40]. Larval density in the Lacandon forest breeding habitats is in concordance with the densities reported in other countries, which are never abundant [5].

In Mexico, An. darlingi is not considered a primary malaria vector in the Lacandon forest region [12], for several possible reasons. One hypothesis is the low larval and therefore adult densities. In a study of incrimination of Anopheles spp in the Lacandon forest, only 21 (0.6\%) specimens of An. darlingi were collected with human baiting during 6 months (June-November) and all were negative for malaria parasites [12]. This shows the low density of this species in the Lacandon forest region. Another explanation could be that the population belongs to genotype 2 (northern population), which is reported in Belize, Guatemala, and Colombia, where this genotype is considered a secondary vector. Genotype 1 (southern population) is reported in the Amazon forest and Brazil, where it is abundant and is considered a primary vector in places with high incidence of $P$. vivax and $P$. falciparum malaria [41-43]. None of the reported molecular studies for this important malaria vector have included Mexican populations. Therefore, the genetic relationship between Mexican An. darlingi populations and those of Central and South America is unknown. It is necessary to continue studying this important malaria vector in the Neotropical region, with the aim to elucidate its role in the transmission of malaria in Mexico and take the necessary control measures.

Anopheles darlingi larvae were found only in the Lacandon forest region (Fig. 1). However, periodical sampling is required in the Soconusco region in southern Chiapas, as well as to extend the study area to other states such as Quintana Roo, Tabasco and Veracruz because the presence of this mosquito is expected at these places [44].

Taking into account this study findings and as part of a programme of vector larval control strategies, priority 
should be given to control positive types of habitat of $A n$ darling $i$ and coexisting species that occur at the start of the rainy season, especially in breeding sites containing algae with little current or stagnant water and located near to human settlements. To control these breeding site habitats an environmental management like removing algae and/or a biorational insecticide application can be undertaken. This study is the first of its kind by the amplitude and diversity of habitats that were examined in the Lacandon forest and Soconusco region and is useful to develop sustainable control strategies in this important focus of malaria in the South of Mexico.

\section{Conclusions}

This study has demonstrated that the habitat stability, presence of algae and water current were the main factors for An. darlingi larval occurrence. The information on the characteristics of the larval habitats of An. darlingi will be useful in sustainable programmes for malaria control in the region of the Lacandon forest, Chiapas.

\section{Additional file}

Additional file 1: Hydrological types positive and negative to Anopheles darlingi larvae in the Lacandon forest region, Chiapas, México.

\section{Abbreviations}

LI: larval index; SD: standard deviation.

\section{Authors' contributions}

CVT and ADR conceived the study design, participated in field data collection, data analysis and writing the manuscript. RPPN and MGVM contributed with data analysis, the discussion and writing the manuscript. JCRD carried out field data collection, mosquito rearing, entomological identification and writing the manuscript. DAML carried out data analysis and writing the manuscript. IFS was involved in the statistical analysis, interpretation and discussion and revised the final manuscript. All authors read and approved the final manuscript.

\section{Acknowledgements}

Financial support was provided by Consejo Nacional de Ciencia y Tecnología (CONACYT) México, Grant 105806. The funders had no role in study design, data collection and analysis, decision to publish, or preparation of the manuscript.

\section{Competing interests}

The authors declare that they have no competing interests.

Received: 16 September 2015 Accepted: 4 December 2015 Published online: 22 December 2015

\footnotetext{
References

1. WHO. World malaria report. Geneva: World Health Organization; 2014

2. Faran ME, Linthicum KJ. A handbook of the Amazonian species of Anopheles (Nyssorhynchus) (Diptera: Culicidae). Mosq Syst. 1981;13:1-81.

3. Hiwat H, Bretas G. Ecology of Anopheles darlingi root with respect to vector importance: a review. Parasit Vectors. 2011;4:177. doi:10.1186/1756-3305-4-177.
}

4. Knight KL, Stone A. A Catalog of the mosquitoes of the world (Diptera: Culicidae). Thomas Say Foundation Second edition. 1977;6:1-10.

5. Linthicum KJ. A revision of the Argyritarsus section of the subgenus Nyssorhynchus of Anopheles (Diptera: Culicidae). Mosq Syst. 1988;20:98-271.

6. Loaiza J, Scott M, Bermingham E, Rovira J, Sanjur O, Conn JE. Anopheles darlingi (Diptera: Culicidae) in Panama. Am J Trop Med Hyg. 2009;81:23-6.

7. Vittor AY, Gilman RH, Tielsch J, Glass G, Shields T, Lozano WS, et al. The effect of deforestation on the human-biting rate of Anopheles darlingi, the primary vector of falciparum malaria in the Peruvian Amazon. Am J Trop Med Hyg. 2006;74:3-11.

8. Aramburu Guarda J, Ramal Asayag C, Witzig R. Malaria reemergence in the Peruvian Amazon region. Emerg Infect Dis. 1999;5:209-15.

9. Pinedo-Cancino V, Sheen P, Tarazona-Santos E, Oswald WE, Jeri C, Vittor AY, et al. Limited diversity of Anopheles darlingi in the Peruvian Amazon region of lquitos. Am J Trop Med Hyg. 2006;75:238-45.

10. Naranjo-Diaz N, Rosero DA, Rua-Uribe G, Luckhart S, Correa MM. Abundance, behavior and entomological inoculation rates of anthropophilic anophelines from a primary Colombian malaria endemic area. Parasit Vectors. 2013;6:61. doi:10.1186/1756-3305-6-61.

11. Grieco JP, Achee NL, Roberts DR, Andre RG. Comparative susceptibility of three species of Anopheles from Belize, Central America, to Plasmodium falciparum (NF-54). J Am Mosq Control Assoc. 2005;21:279-90.

12. Loyola EG, Arredondo-Jimenez Jl, Rodriguez MH, Bown DN, Vaca-Marin MA. Anopheles vestitipenis, the probable vector of Plasmodium vivax in the Lacandon forest of Chiapas, Mexico. Trans R Soc Trop Med Hyg. 1991:85:171-4.

13. Villarreal-Treviño C, Arredondo-Jimenez JI, Malo IR, Rodriguez MH. Colonization of Anopheles darlingi from the Lacandon Forest, Chiapas, Mexico. J Am Mosq Control Assoc. 2001;12:LB0220-21.

14. Manguin S, Roberts DR, Andre RG, Rejmankova E, Hakre S. Characterization of Anopheles darlingi (Diptera: Culicidae) larval habitats in Belize, Central America. J Med Entomol. 1996;33:205-11.

15. Achee NL, Grieco JP, Andre RG, Roberts DR, Rejmankova E. Experimental evaluation of overhanging bamboo in Anopheles darlingi larval habitat selection in Belize, Central America. J Vector Ecol. 2006;31:145-51.

16. Faran ME, Linthicum KJ. A handbook of the Amazonian species of Anopheles (Nyssorhynchus) (Diptera: Culicidae). Mosq Syst. 1981;13:1-81.

17. Brochero HL, Rey G, Buitrago LS, Olano VA. Biting activity and breeding sites of Anopheles species in the municipality Villavicencio, Meta, Colombia. J Am Mosq Control Assoc. 2005;21:182-6.

18. Tadei WP, Thatcher BD, Santos JM, Scarpassa VM, Rodrigues IB, Rafael MS Ecologic observations on anopheline vectors of malaria in the Brazilian Amazon. Am J Trop Med Hyg. 1998;59:325-35.

19. Betanzos-Reyes A. La malaria en México. Progresos y desafíos hacia su eliminación. Bol Med Hosp Infant Mex. 2011;68:159-68.

20. Kumm H, Bustamante ME, Herrera JR. Report concerning anophelines found near the Mexican-Guatemalan frontier. Am J Trop Med Hyg 1943;23:373-6.

21. Vargas L. Anopheles darlingi Root, 1926 en México. Rev del Inst de Salubry Enferm Trop. 1946;4:221-6.

22. Vargas L, Martínez-Palacios A. Anofelinos mexicanos, Taxonomía y Distribución. México City: Comisión Nacional para la Erradicación del Paludismo: Secretaría de Salubridad y Asistencia; 1956. p. 141, 145.

23. INE. Instituto Nacional de Ecología: Programa de Manejo Reserva de la Biosfera Montes Azules. México. México: Instituto Nacional de Ecología, Secretaría del Medio Ambiente, Recursos Naturales y Pesca; 2000. p. 11-23.

24. Vittor AY, Pan W, Gilman RH, Tielsch J, Sánchez-Lozano W, Salas-Cobos E, et al. Linking deforestation to malaria in the Amazon: characterization of the breeding habitat of the principal malaria vector, Anopheles darlingi. Am J Trop Med Hyg. 2009;81:5-12.

25. MAP. Malaria Atlas Project. http://www.map.ox.ac.uk.

26. Danis-Lozano R, Rodríguez MH, Betanzos-Reyes AF, Hernández-Avila JE, González-Cerón L, Méndez-Galván JF, et al. Individual risk factors for Plasmodium vivax infection in the residual malaria transmission focus of Oaxaca, Mexico. Salud Pública Mex. 2007;49:199-209.

27. Comisión Nacional del Agua. Servicio Meteorológico Nacional. http://smn. cna.gob.mx/index.php.

28. Chirebvu E, Chimbari MJ. Characteristics of Anopheles arabiensis larval habitats in Tubu village, Botswana. J Vector Ecol. 2015;40:129-38. doi:10.1111/jvec.12141. 
29. Vázquez-Martínez MG, Rodríguez MH, Arredondo-Jiménez Jl, MéndezSanchez JD, Bond-Compeán JG, Cold-Morgan M. Cyanobacteria associated with Anopheles albimanus (Diptera: Culicidae) larval habitats in southern Mexico. J Med Entomol. 2002;39:825-32.

30. Wilkerson RC, Strickman D, Litwak TR. Illustrated key to the female anopheline mosquitoes of Central America and Mexico. J Am Mosq Control Assoc. 1990;6:7-34.

31. WHO. Manual on practical entomology in malaria. Part II. Methods and techniques. Geneva: World Health Organization; 1975. p. 55-68.

32. Mwangangi JM, Shililu J, Muturi EJ, Jacob B, Kabiru EW, et al. Anopheles larval abundance and diversity in three rice agro-village complexes Mwea irrigation scheme, central Kenya. Malar J. 2010;9:228. doi:10.1186/1475-2875-9-228.

33. Gouagna LC, Rakotondranary M, Boyer S, Lempérière G, Dehecq JS, Fontenille D. Abiotic and biotic factors associated with the presence of Anopheles arabiensis immatures and their abundance in naturally occurring and man-made aquatic habitats. Parasit Vectors. 2012;5:96. doi:10.1186/1756-3305-5-96.

34. Kenea O, Balkew M, Gebre-Michael T. Environmental factors associated with larval habitats of anopheline mosquitoes (Diptera: Culicidae) in irrigation and major drainage areas in the middle course of the Rift Valley, central Ethiopia. J Vector Borne Dis. 2011;48:85-92.

35. Rozendaal JA. Relations between Anopheles darlingi breeding habitats, rainfall, river level and malaria transmission rates in the rain forest of Suriname. Med Vet Entomol. 1992;6:16-22.

36. Yasuoka J, Levins R. Impact of deforestation and agricultural development on anopheline ecology and malaria epidemiology. Am J Trop Med Hyg. 2007;76:450-60.

37. Rubio-Palis Y, Bevilacqua M, Medina DA, Moreno JE, Cárdenas L, Sánchez $\checkmark$, et al. Malaria entomological risk factors in relation to land cover in the Lower Caura River Basin, Venezuela. Mem Inst Oswaldo Cruz. 2013;108:220-8. doi:10.1590/0074-0276108022013015.
38. Ortega MAI, Avila PM, Elizondo-Quiroga A, Harbach RE, Quetzaly K, Siller-Rodríguez QK, et al. The mosquitoes of Quintana Roo State, México (Diptera: Culicidae). Acta Zool Mex. 2010;26:33-46.

39. Roberts DR, Paris JF, Manguin S, Harbach RE, Woodruff R, Rejmankova E, et al. Predictions of malaria vector distribution in Belize based on multispectral satellite data. Am J Trop Med Hyg. 1996;54:304-8.

40. Vázquez-Martínez MG, Rodríguez MH, Arredondo-Jiménez Jl, MéndezSánchez JD. Phormidium animalis (Cyanobacteria: Oscillatoriaceae) supports larval development of Anopheles albimanus. J Am Mosq Control Assoc. 2003;19:155-8.

41. Mirabello L, Vineis JH, Yanoviak SP, Scarpassa VM, Povoa MM, Padilla N, et al. Microsatellite data suggest significant population structure and differentiation within the malaria vector Anopheles darlingi in Central and South America. BMC Ecol. 2008;8:3. doi:10.1186/1472-6785-8-3.

42. Conn JE, Mirabello L. The biogeography and population genetics of neotropical vector species. Heredity. 2007;99:245-56. doi:10.1038/ sj.hdy.6801002.

43. Mirabello L, Conn JE. Molecular population genetics of the malaria vector Anopheles darlingi in central and South America. Heredity. 2006;96:31121. doi:10.1038/sj.hdy.6800805.

44. Sinka ME, Rubio-Palis Y, Manguin S, Patil AP, Temperley WH, Gething PW, et al. The dominant Anopheles vectors of human malaria in the Americas: occurrence data, distribution maps and bionomic précis. Parasit Vectors. 2010;3:72. doi:10.1186/1756-3305-3-72

\section{Submit your next manuscript to BioMed Central and we will help you at every step:}

- We accept pre-submission inquiries

- Our selector tool helps you to find the most relevant journal

- We provide round the clock customer support

- Convenient online submission

- Thorough peer review

- Inclusion in PubMed and all major indexing services

- Maximum visibility for your research

Submit your manuscript at www.biomedcentral.com/submit

() Biomed Central 